GSA Data Repository 2016327

\title{
Sea-surface temperature evolution across Aptian Oceanic Anoxic Event 1a
}

\section{Naafs and Pancost}

\section{Supplementary information}

\section{Detailed methods}

Lipids from DSDP Site 398 were obtained by extracting 14 grams of dry sediment with an Ethos Ex microwave extraction system with a $20 \mathrm{ml}$ of a mixture dicloromethane (DCM) and methanol $(\mathrm{MeOH})(9: 1, \mathrm{v} / \mathrm{v})$. The microwave program consisted of a $10 \mathrm{~min}$ ramp to $70{ }^{\circ} \mathrm{C}(1000 \mathrm{~W}), 10 \mathrm{~min}$ hold at $70{ }^{\circ} \mathrm{C}(1000 \mathrm{~W})$, and 20 min cool down. The samples from the Djebel Serdj FM in Tunisia were extracted using between 30 and 40 gram of dry sediment and Soxhlet apparatus for $24 \mathrm{~h}$ using $\mathrm{DCM} / \mathrm{MeOH}(2: 1 \mathrm{v} / \mathrm{v})$. For both sample sets, copper cuttings were added to the total lipid extract (TLE) for $24 \mathrm{hrs}$ to remove elemental sulphur. For Site 398 the TLE was separated into four fractions using silica $(10 \mathrm{ml}$ slurry) flash column chromatography and successive elution with $21 \mathrm{ml}$ of hexane (Hex), $21 \mathrm{ml}$ of DCM:Hex (1:1, v/v), 28 $\mathrm{ml}$ of DCM, and finally $14 \mathrm{ml}$ of $\mathrm{MeOH}$ to obtain the polar fraction that contains the glycerol dialkyl glycerol tetraethers (GDGTs). For Djebel Serdj the TLE was separated into three fractions using silica $(2 \mathrm{ml})$ open column chromatography and successive elution with $3 \mathrm{ml}$ hexane, $4 \mathrm{ml}$ hexane/DCM (3:1 v/v) and $4 \mathrm{ml}$ $\mathrm{DCM} / \mathrm{MeOH}(1: 2 \mathrm{v} / \mathrm{v})$ resulting in apolar, aromatic and polar (GDGT containing) fractions, respectively.

All samples were analyzed for their core-lipid GDGTs distribution by high performance liquid chromatography/atmospheric pressure chemical ionisation - mass spectrometry (HPLC/APCI-MS) using a ThermoFisher Scientific Accela Quantum Access triplequadrupole MS at the Organic Geochemistry Unit. Normal phase separation was achieved using two ultra-high performance liquid chromatography silica columns, following Hopmans et al. (2016). Injection volume was $15 \mu$, typically from $100 \mu \mathrm{l}$. Analyses were performed using selective ion monitoring mode (SIM) to increase sensitivity and reproducibility $(\mathrm{m} / \mathrm{z}$ 1302, 1300, 1298, 1296, 1294, 1292, 1050, 1048, 1046, 1036, 1034, 1032, 1022, 1020, 1018, 744, and 653). Samples were integrated manually using the Xcalibur software.

\section{Definition of $\mathrm{TEX}_{86}$ and $\mathrm{TEX}_{86}{ }^{\mathrm{H}}$ and SST calibrations over time}

Schouten et al. (2002) defined $\mathrm{TEX}_{86}$ as a ratio of the distribution of isoprenoidal glycerol dialkyl glycerol diethers (GDGTs), archaeal membrane-spanning lipids.

$$
T E X_{86}=\frac{[G D G T-2]+[G D G T-3]+\left[\mathrm{cren}^{\prime}\right]}{[G D G T-1]+[G D G T-2]+[G D G T-3]+\left[\mathrm{cren}^{\prime}\right]}
$$

35

They proposed a linear correlation between $\mathrm{TEX}_{86}$ and SST proxy using marine sediments from across the world $(n=40)$.

$$
T E X_{86}=0.015 \times S S T-0.27 \quad \text { giving } \quad S S T\left({ }^{\circ} \mathrm{C}\right)=66.7 \times T E X_{86}+18
$$


A linear correlation between temperature and $\mathrm{TEX}_{86}$ was confirmed for temperature up to $40{ }^{\circ} \mathrm{C}$ by incubation and mesocom experiments (Schouten et al., 2007; Wuchter et al., 2004).

$$
T E X_{86}=0.017 \times S S T+0.064 \text { giving } S S T\left({ }^{\circ} \mathrm{C}\right)=58.8 \times T E X_{86}-3.8
$$

Although the intercept of this calibration differed from that found in marine core-tops, predominantly due to a difference in the amount of crenarchaeol regioisomer, the slope was comparable with that found in marine core-tops.

Kim et al. (2008) provided an updated linear calibration, based on 223 coretop samples with a global distribution.

$$
T E X_{86}=0.018 \times S S T+0.19 \text { giving } \quad S S T\left({ }^{\circ} \mathrm{C}\right)=56.2 \times T E X_{86}-10.78
$$

Although all previous studies used a linear correlation between $\mathrm{TEX}_{86}$ and temperature, including the incubation and mesocom experiments, Kim et al. (2010) proposed a logarithmic correlation between temperature and $\mathrm{TEX}_{86}$ for samples from core-tops with an overlying SST $>15^{\circ} \mathrm{C}$ : “TEX ${ }_{86}^{\mathrm{H}}$ ".

$$
\begin{aligned}
\log \left(T E X_{86}\right)= & 0.015 \times S S T-0.56 \text { giving } S S T\left({ }^{\circ} \mathrm{C}\right) \\
& =68.4 \times \log \left(T E X_{86}\right)+38.6
\end{aligned}
$$

We note that Kim et al. (2010) also proposed an alternative ratio and calibration: $\mathrm{TEX}_{86}^{\mathrm{L}}$. Different from all other calibrations $\mathrm{TEX}_{86}{ }^{\mathrm{L}}$ is not based on the original $\mathrm{TEX}_{86}$ index.

$$
\operatorname{SST}\left({ }^{\circ} \mathrm{C}\right)=67.5 \times \log \left(\frac{[G D G T-2]}{[G D G T-1]+[G D G T-2]+[G D G T-3]}\right)+46.9
$$

Recently, the $\mathrm{TEX}_{86}{ }^{\mathrm{L}}$ approach has been vigorously critiqued because: 1 ) the ratio of GDGT-2 to the sum of GDGT-1, -2 and -3 has no phsysiological basis, unlike the original $\mathrm{TEX}_{86}$ ratio that records an increasing degree of cyclisation at higher temperatures(Schouten et al., 2002; Schouten et al., 2013)); 2) it has structured temperature residuals at the high end of the calibration, which is particularly problematic for its application to warm climates of the past (Tierney and Tingley, 2014); and 3) sub-surface GDGT distributions are characterized by high ratios of GDGT-2 to GDGT-3, meaning that export dynamics are particularly problematic for this proxy (Hernández-Sánchez et al., 2014; Taylor et al., 2013). As such, we do not use $\mathrm{TEX}_{86}{ }^{\mathrm{L}}$ here.

\section{Deep time analogue calibration}

In order to create a deep time analogue calibration for OAE 1a we compiled all TEX 86 records that span OAE 1a Fig. 2. The deep-time model of BAYSPAR selects TEX 86 values from the modern dataset with a similar $\mathrm{TEX}_{86}$ value to that of the paleorecord and then uses these locations to construct a linear regression (Tierney and Tingley, 2014). For this purpose the model requires an estimate of the prior distribution of the unknowns (basically a prediction of the SSTs to be estimated). We selected a value of $30{ }^{\circ} \mathrm{C}$ and a broad standard deviation of $20^{\circ} \mathrm{C}$. Selecting different values (e.g. $25-$ $35^{\circ} \mathrm{C}$ as priors or smaller standard deviation) does not lead to different SSTs. The 
search tolerance was 0.17 ( $2 \sigma$ of the inputted $\mathrm{TEX}_{86}$ data). The resulting linear calibration is based on "analogue" locations from the modern tropics and Red Sea.

$$
T E X_{86}=0.016 \times S S T+0.25 \text { giving } \quad S S T\left({ }^{\circ} \mathrm{C}\right)=60.9 \times T E X_{86}-15.6
$$

We note that much of our data fall beyond the modern calibration range, but the Bayesian approach of the BAYSPAR deep time analogue incorporates that into its error calculation.

\section{Linear $\mathrm{TEX}_{86}$ calibration using all modern core tops with $\mathrm{SST}>15{ }^{\circ} \mathrm{C}$}

In addition to using the BAYSPAR deep time analogue model to create a linear calibration, we also generated a new linear $\mathrm{TEX}_{86}$ calibration using all modern core top data underlying surface waters with SST $>15^{\circ} \mathrm{C}$ (Fig. DR1). The cut-off of $15^{\circ} \mathrm{C}$ is identical to that used by $\mathrm{TEX}_{86}{ }^{\mathrm{H}}$, but instead of a logarithmic correlation we use a linear correlation.

$$
T E X_{86}=0.017 \times S S T+0.22 \text { giving } \quad S S T\left({ }^{\circ} \mathrm{C}\right)=58.8 \times T E X_{86}-13.4
$$

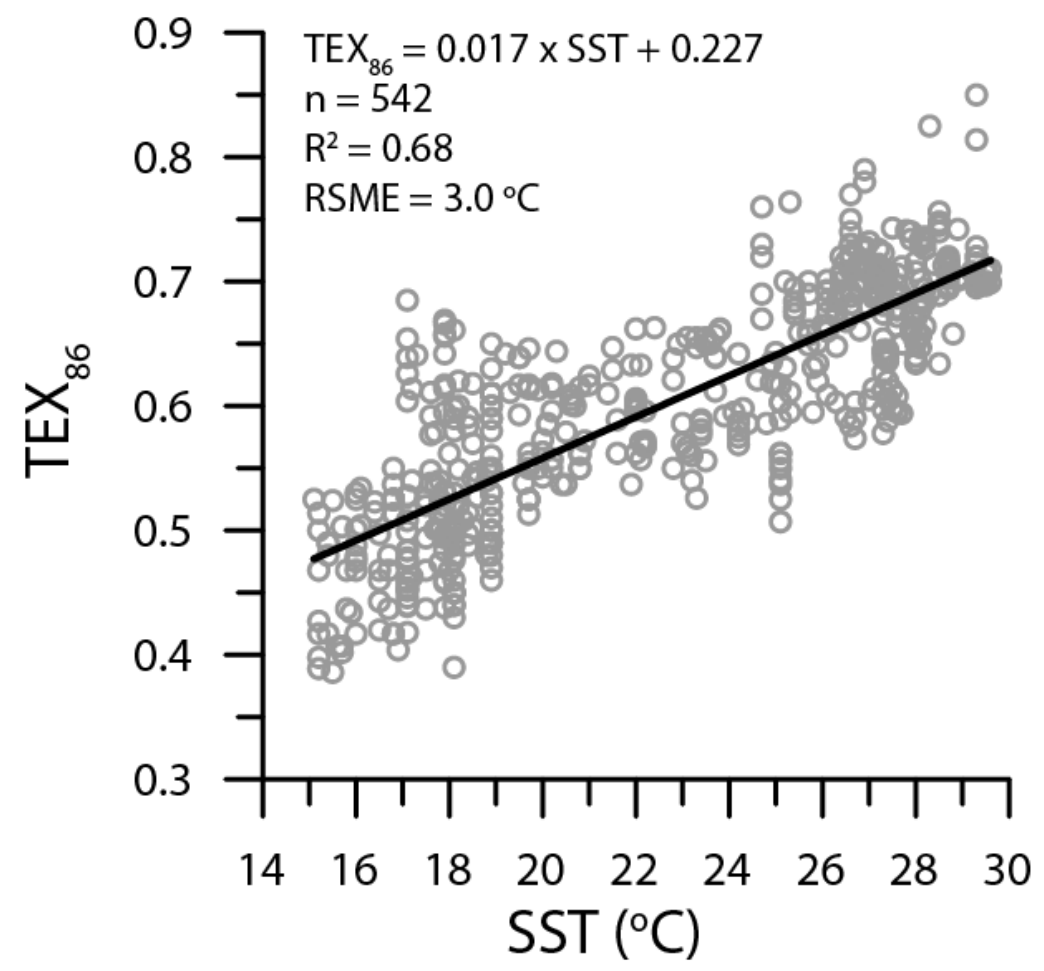

Figure DR1: Newly constructed linear TEX $X_{86}$ calibration based on all core top data from regions with SST $>15{ }^{\circ} \mathrm{C}$. Data from Tierney and Tingley (2015)

The slope of the new linear calibration is $\sim 60$, virtually identical that that of the deep time analogue approach, and both of those are very similar to the slope of the high temperature calibration obtained from the incubation experiments at temperatures between 10 and $40{ }^{\circ} \mathrm{C}$ (Schouten et al., 2007).

Using the newly constructed calibration to generate latitudinal SST gradients for OAE 1a gives results that are nearly identical to those obtained using the 
BAYSPAR deep time analogue approach with a pronounced latitudinal gradient (Fig. DR2). It also gives nearly identical temporal trends through OAE1a at DSDP Site

112398.

113

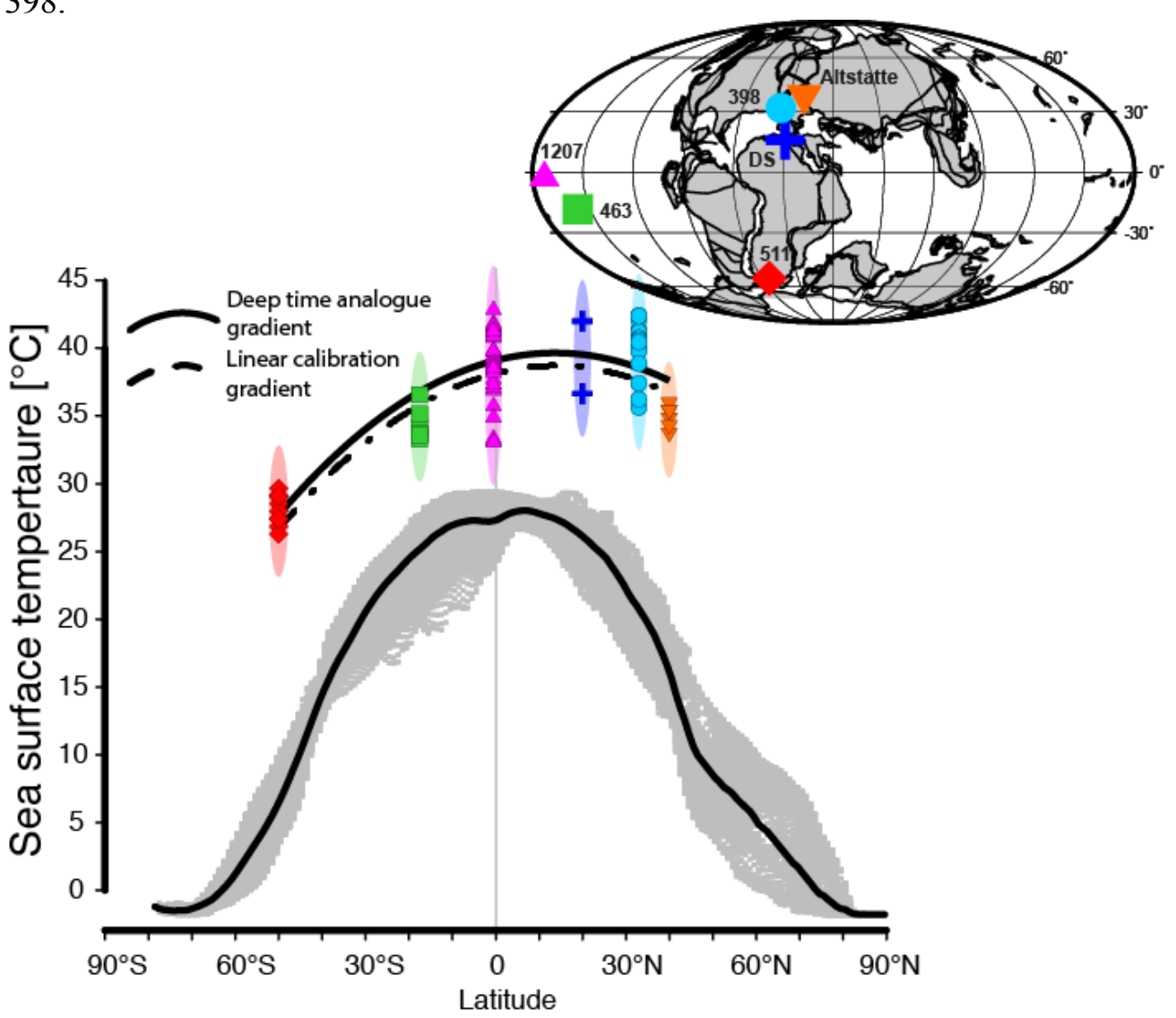

Figure DR2: Latitudinal SST gradient for OAE 1a using the newly constructed linear $T E X_{86}$ calibration, based on modern-day samples from regions with $S S T>15^{\circ} \mathrm{C}$ only. The deeptime analogue gradient is the same as shown in Figure $2 a$ and $b$. Error bars reflect RSME of calibration, which is $3^{\circ} \mathrm{C}$.

\section{Supplementary references}

Hernández-Sánchez, M. T., Woodward, E. M. S., Taylor, K. W. R., Henderson, G. M., and Pancost, R. D., 2014, Variations in GDGT distributions through the water column in the South East Atlantic Ocean: Geochimica et Cosmochimica Acta, v. 132, p. 337-348, doi: 10.1016/j.gca.2014.02.009.

Hopmans, E. C., Schouten, S., and Sinninghe Damsté, J. S., 2016, The effect of improved chromatography on GDGT-based palaeoproxies: Organic Geochemistry, v. 93, p. 1-6, doi: 10.1016/j.orggeochem.2015.12.006.

Kim, J.-H., Schouten, S., Hopmans, E. C., Donner, B., and Sinninghe Damsté, J. S., 2008, Global sediment core-top calibration of the $\mathrm{TEX}_{86}$ paleothermometer in the ocean: Geochimica et Cosmochimica Acta, v. 72, no. 4, p. 1154-1173, doi: 10.1016/j.gca.2007.12.010.

Kim, J.-H., van der Meer, J., Schouten, S., Helmke, P., Willmott, V., Sangiorgi, F., Koç, N., Hopmans, E. C., and Sinninghe Damsté, J. S., 2010, New indices and calibrations derived from the distribution of crenarchaeal isoprenoid tetraether 
lipids: Implications for past sea surface temperature reconstructions: Geochimica et Cosmochimica Acta, v. 74, no. 16, p. 4639-4654, doi: 10.1016/j.gca.2010.05.027.

Schouten, S., Forster, A., Panoto, F. E., and Sinninghe Damsté, J. S., 2007, Towards calibration of the $\mathrm{TEX}_{86}$ palaeothermometer for tropical sea surface temperatures in ancient greenhouse worlds: Organic Geochemistry, v. 38, no. 9, p. 1537-1546, doi: 10.1016/j.orggeochem.2007.05.014.

Schouten, S., Hopmans, E. C., Schefuss, E., and Sinninghe Damsté, J. S., 2002, Distributional variations in marine crenarchaeotal membrane lipids: a new tool for reconstructing ancient sea water temperatures?: Earth and Planetary Science Letters, v. 204, no. 1-2, p. 265-274, doi: 10.1016/S0012821X(02)00979-2.

Schouten, S., Hopmans, E. C., and Sinninghe Damsté, J. S., 2013, The organic geochemistry of glycerol dialkyl glycerol tetraether lipids: A review: Organic Geochemistry, v. 54, p. 19-61, doi: 10.1016/j.orggeochem.2012.09.006.

Taylor, K. W. R., Huber, M., Hollis, C. J., Hernandez-Sanchez, M. T., and Pancost, R. D., 2013, Re-evaluating modern and Palaeogene GDGT distributions: Implications for SST reconstructions: Global and Planetary Change, v. 108, p. 158-174, doi: 10.1016/j.gloplacha.2013.06.011.

Tierney, J. E., and Tingley, M. P., 2014, A Bayesian, spatially-varying calibration model for the TEX 86 proxy: Geochimica et Cosmochimica Acta, v. 127, p. 83106, doi: 10.1016/j.gca.2013.11.026.

-, 2015, A TEX 86 surface sediment database and extended Bayesian calibration: Scientific Data, v. 2, p. 150029, doi: 10.1038/sdata.2015.29.

Wuchter, C., Schouten, S., Coolen, M. J. L., and Sinninghe Damsté, J. S., 2004, Temperature-dependent variation in the distribution of tetraether membrane lipids of marine Crenarchaeota: Implications for $\mathrm{TEX}_{86}$ paleothermometry: Paleoceanography, v. 19, no. 4, p. PA4028, doi: 10.1029/2004PA001041. 


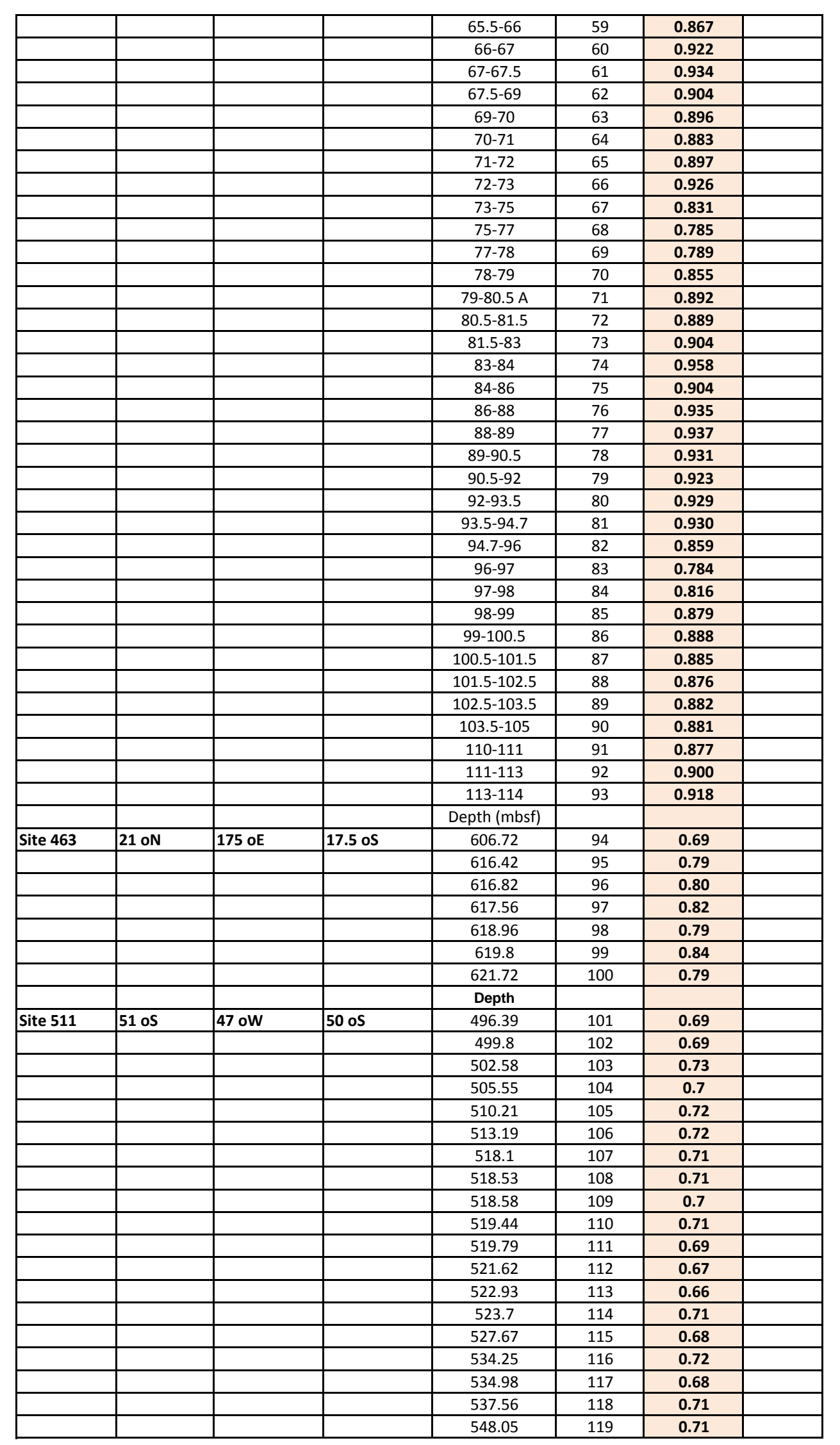

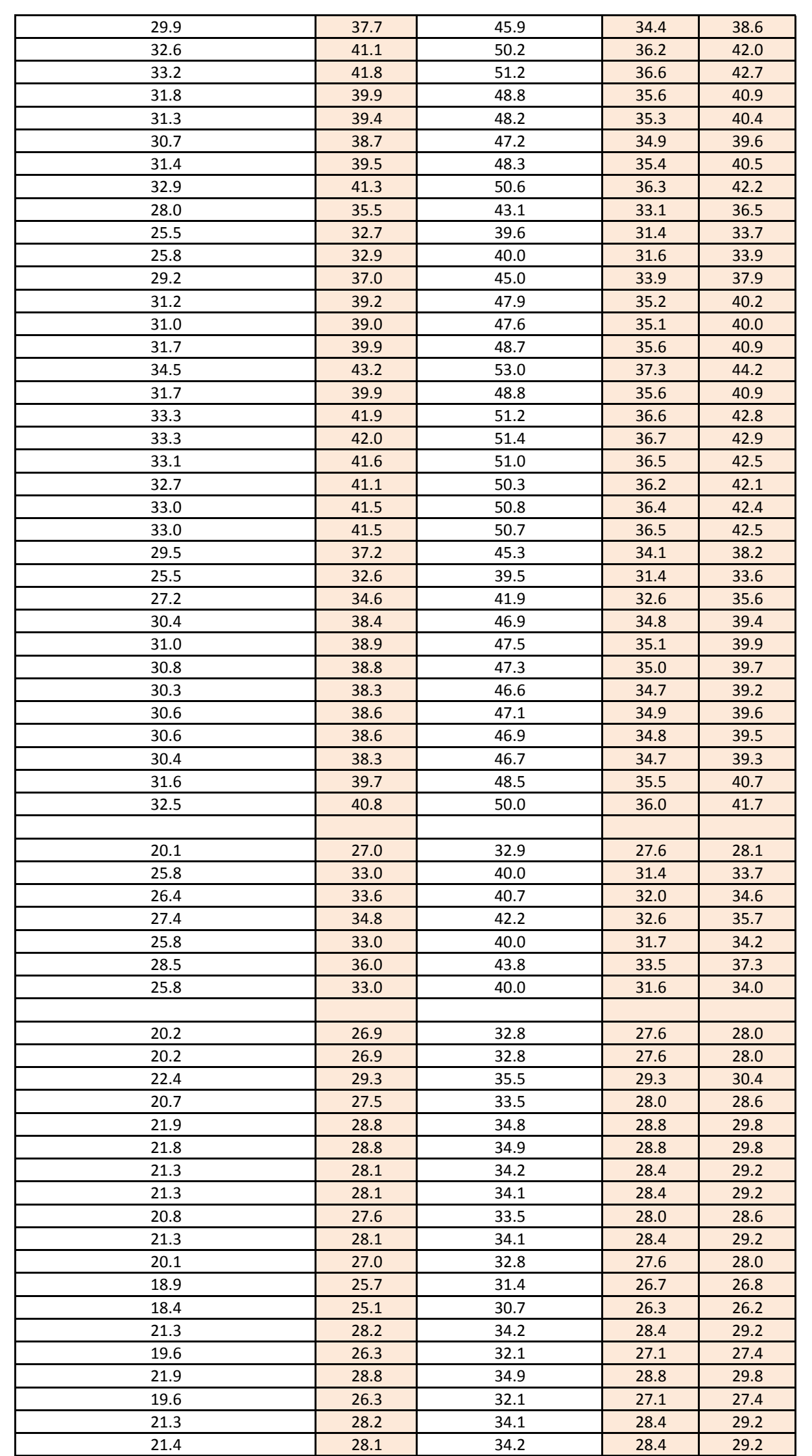




\begin{tabular}{|c|c|c|c|c|c|c|c|}
\hline & & & & $\begin{array}{r}552.33 \\
553.34\end{array}$ & $\frac{120}{121}$ & $\frac{0.72}{0.71}$ & \\
\hline & & & & 553.79 & 122 & 0.73 & \\
\hline & & & & 556.63 & 123 & 0.74 & \\
\hline & & & & 566.4 & 124 & 0.74 & \\
\hline & & & & 567.15 & 125 & 0.75 & \\
\hline & & & & 568.6 & 126 & 0.71 & \\
\hline & & & & 572.57 & 127 & 0.73 & \\
\hline & & & & 575.58 & 128 & 0.74 & \\
\hline & & & & 576.81 & 129 & 0.72 & \\
\hline & & & & 578.55 & 130 & 0.73 & \\
\hline & & & & 579.83 & 131 & 0.71 & \\
\hline & & & & 580.99 & 132 & 0.71 & \\
\hline & & & & 584.5 & 133 & 0.7 & \\
\hline & & & & 587.1 & 134 & 0.71 & \\
\hline & & & & 588.13 & 135 & 0.72 & \\
\hline & & & & 588.95 & 136 & 0.72 & \\
\hline & & & & 589.31 & 137 & 0.7 & \\
\hline & & & & 590.29 & 138 & 0.72 & \\
\hline & & & & 591.37 & 139 & 0.73 & \\
\hline & & & & $\begin{array}{l}391.01 \\
50101\end{array}$ & 140 & 0.12 & \\
\hline & & & & S39.01 & 141 & 0.12 & \\
\hline & & & & $\frac{53.037}{507}$ & 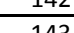 & 0 & \\
\hline & & & & 500.07 & 145 & 0.10 & \\
\hline & & & & & 144 & 0.1 & \\
\hline Djebel Serdj & 36 oN & $10 \mathrm{oE}$ & $20 \mathrm{oN}$ & MF8 & 145 & 0.94 & \\
\hline & & & & MF21 & 146 & 0.84 & 0 \\
\hline
\end{tabular}

\begin{tabular}{|c|c|c|c|c|}
\hline 21.9 & 28.8 & 34.9 & 28.8 & 29.8 \\
\hline 21.3 & 28.1 & 34.2 & 28.4 & 29.2 \\
\hline 22.4 & 29.4 & 35.6 & 29.3 & 30.4 \\
\hline 23.1 & 30.0 & 36.4 & 29.7 & \\
\hline 23.1 & 30.0 & 36 & 29.7 & \\
\hline 23.5 & 30.6 & 37.1 & 30.1 & 31.6 \\
\hline 21.3 & 28.2 & 34.2 & 28.4 & 29.2 \\
\hline 22.5 & 29.4 & 35.6 & 29.3 & 30.4 \\
\hline 23.0 & 29.9 & 36.3 & 29.7 & 31.0 \\
\hline 21.9 & 28.8 & 35.0 & 28.8 & 29.8 \\
\hline 22.4 & 29.4 & 35.5 & 29.3 & 30.4 \\
\hline 21.4 & 28.2 & 34.1 & 28.4 & 29.2 \\
\hline 21.3 & 28.1 & 34.2 & 28.4 & 29.2 \\
\hline 20.7 & 27.5 & 33.5 & 28.0 & 28.6 \\
\hline 21.3 & 28.2 & 3.1 & 28.4 & 29.2 \\
\hline 21.9 & 28.1 & 34.9 & 28.8 & 29.8 \\
\hline & 28.8 & 34.9 & 28.8 & 29.8 \\
\hline 20.1 & 27.6 & 33.5 & 28.0 & 28.6 \\
\hline 22.0 & 28.8 & 34.9 & 28.8 & 29.8 \\
\hline 2.4 & 29.4 & 33.6 & 29.3 & 30.4 \\
\hline 21.9 & 20.0 & 34.9 & 20.0 & 29.8 \\
\hline 21.5 & 20.0 & 34.5 & 20.0 & 29.8 \\
\hline$\frac{2.15}{201}$ & 20.1 & 34.5 & 20.0 & 29.8 \\
\hline 2,1 & 0 & 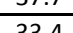 & 30.4 & 32.2 \\
\hline & & 3.4 & & \\
\hline 33.6 & 42.2 & 51.7 & 36.8 & 43.1 \\
\hline 28.5 & 36.0 & 43.7 & 33.4 & 37.0 \\
\hline
\end{tabular}

